\title{
(C) OPEN ACCESS \\ Rotator cuff tear following long-standing axillary neuropathy in a female motocross racer
}

\author{
John G Skedros, ${ }^{1,2}$ Tanner R Henrie, ${ }^{1}$ Mitchell D Peterson ${ }^{1}$
}

${ }^{1}$ Department of Orthopaedic Surgery, The University of Utah, Salt Lake City, Utah, USA ${ }^{2}$ Orthopaedic Surgery, Intermountain Medical Center, Murray, Utah, USA

Correspondence to Dr John G Skedros, jskedrosmd@uosmd.com

Accepted 23 May 2018

Check for updates

To cite: Skedros JG Henrie TR, Peterson MD. BMJ Case Rep Published Online First: [please include Day Month Year]. doi:10.1136/ bcr-2017-223692

\section{SUMMARY}

A 'terrible triad' of anterior shoulder dislocation, axillary nerve damage and rotator cuff tear has been previously described. However, we are unaware of any report of anterior shoulder dislocation, humeral fracture, axillary neuropathy and subsequent rotator cuff tear requiring surgery when the axillary neuropathy was deemed permanent. We report the case of a 20-year-old woman who fell in a motocross accident and had an anterior shoulder dislocation, humeral fracture and axillary neuropathy. The fracture was treated surgically with open reduction and internal fixation. The axillary nerve injury was ultimately permanent. Thirteen months after the motocross accident, the patient sustained a rotator cuff tear from seemingly minor trauma. However, several months of aggressive physical therapy preceded the rotator cuff tear. The tear was repaired and the patient was followed for 5 years after the initial injury. She returned to competing in motocross, even though the axillary neuropathy remained complete and permanent.

\section{BACKGROUND}

Major shoulder injuries (dislocations and fractures) can cause varying degrees of neuropathy, with the axillary nerve being most commonly affected. ${ }^{12}$ Fractures of the proximal humerus can also cause axillary neuropathy which can significantly impair recovery of shoulder strength and motion. ${ }^{2} \mathrm{~A}$ traction type of injury is what usually causes the axillary neuropathy seen with an anterior shoulder dislocation or proximal humerus fracture. ${ }^{34} \mathrm{~A}$ 'terrible triad' of anterior shoulder dislocation, axillary nerve injury and rotator cuff tear has been described. ${ }^{5-7}$ A glenoid rim fracture may be associated with this triad, thereby forming a 'terrible tetrad'.

Complete/permanent axillary neuropathy caused by anterior shoulder dislocation with proximal humerus fracture in association with a subsequent (ie, many months later) rotator cuff tear has, to our knowledge, not been reported in the literature. We report the case of a 20-year-old woman who suffered an anterior shoulder dislocation, proximal humerus fracture and axillary nerve damage after a motocross accident. Thirteen months after successful open reduction internal fixation (ORIF) to repair this fracture, she sustained a posterior-superior rotator cuff tear from a seemingly minor traumatic event. In the perspective that the deltoid muscle (supplied by the axillary nerve) is an important stabiliser of the humeral head, ${ }^{9}$ we surmised that shoulder subluxations during aggressive exercise and physical therapy probably contributed to intrinsic weakening of her posterior-superior rotator cuff, making it prone to additional injury.

\section{CASE PRESENTATION}

A 20-year-old, left-hand dominant woman (height $167 \mathrm{~cm}$, weight $63 \mathrm{~kg}$, body mass index $22.6 \mathrm{~kg} / \mathrm{m}^{2}$ ) was in a motocross accident in June 2012 when she sustained a three-part fracture dislocation of the left proximal humerus ${ }^{10}$ (figure 1) in addition to axillary nerve injury on the ipsilateral side. Using conscious sedation, the dislocation was reduced in an emergency department on the same day and without difficulty. Three days later an MRI scan was performed and showed no evidence of rotator cuff tears. One week later, she underwent ORIF, which included a metal plate and screws (figure 2) and was performed by JGS. The rotator cuff was found to be intact by gross examination. Numbness in the axillary field was noted before and after surgery.

A nerve conduction study with electromyography was done 6 months after the shoulder trauma. The results of this study showed severe left axillary neuropathy with ongoing denervation and no evidence for reinnervation and possible additional mild injury to the suprascapular nerve.

In May 2013 (11 months after her initial injury), she had increasing shoulder subacromial crepitus and anterior glenohumeral stiffness, which was treated with arthroscopic debridement of subacromial bursitis with acromioplasty, arthroscopic anterior capsular release and open deep metal removal. Gross examination showed that the supraspinatus insertion was intact and the metal plate was not seen to be causing subacromial impingement. However, supraspinatus tendon thinning was seen but was not given any special consideration at that time.

Nine weeks later, she sustained acute left shoulder pain and motion loss after she pushed herself upward on her arms to lift herself up while sitting on the back of a pickup truck. Her shoulder motion decreased from $120^{\circ}$ to $80^{\circ}$ of active overhead elevation. MR images showed a full-thickness tear of the supraspinatus and upper infraspinatus tendons (figure 3) and a full-thickness tear of the intra-articular biceps tendon. This injury was preceded by several months of aggressive physical therapy and shoulder strengthening and exercise. We speculated these activities, coupled with glenohumeral subluxations from chronic deltoid atrophy, had intrinsically weakened her upper rotator cuff and biceps tendon. An open repair of the rotator 


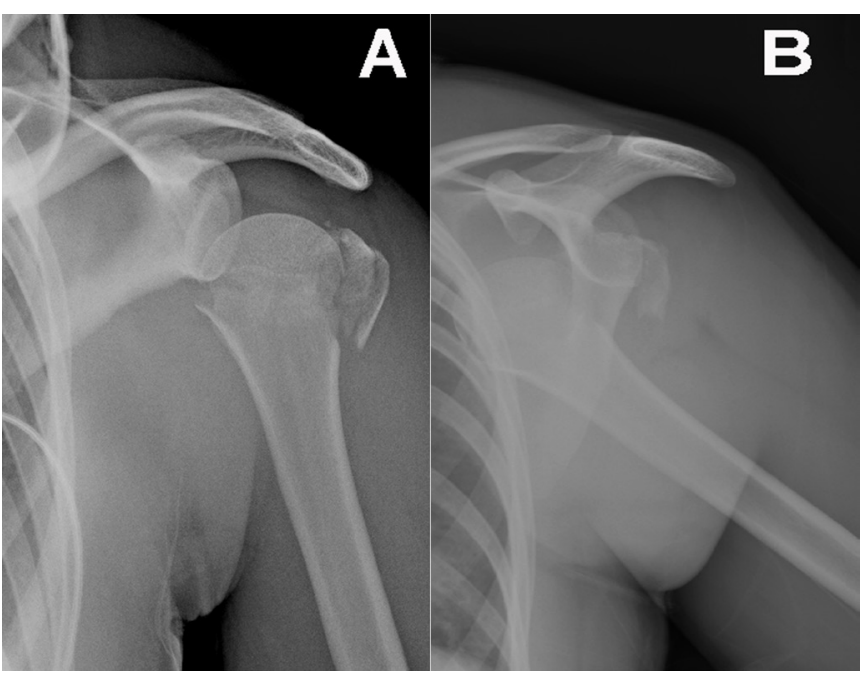

Figure 1 Radiographs from the emergency department showing $(A)$ the postreduction view and the three-part fracture and $(B)$ the dislocation view prior to reduction, which shows the widely displaced greater tuberosity part of the fracture.

cuff tear with biceps tenodesis was performed in July 2013 by JGS.

\section{OUTCOME AND FOLLOW-UP}

At 5 years after the motocross injury to the shoulder of her dominant side and just over 3 years after the rotator cuff repair, the patient's deltoid function had not returned. The patient's shoulder functions and health status before the rotator cuff repair and 3-5 years later are listed in table 1. Despite complete and permanent axillary neuropathy, there was substantial improvement in both pain and ability to perform shoulder-specific tasks. Active flexion and abduction were both $135^{\circ}$ (figure 4). There was also no scapular winging and a negative lift off test. At that time, she had continued mild achy pain of the shoulder with use, but this did not require pain medication other than occasional non-steroidal anti-inflammatory drugs. She had a positive demeanour about the function of her shoulder injury. The patient

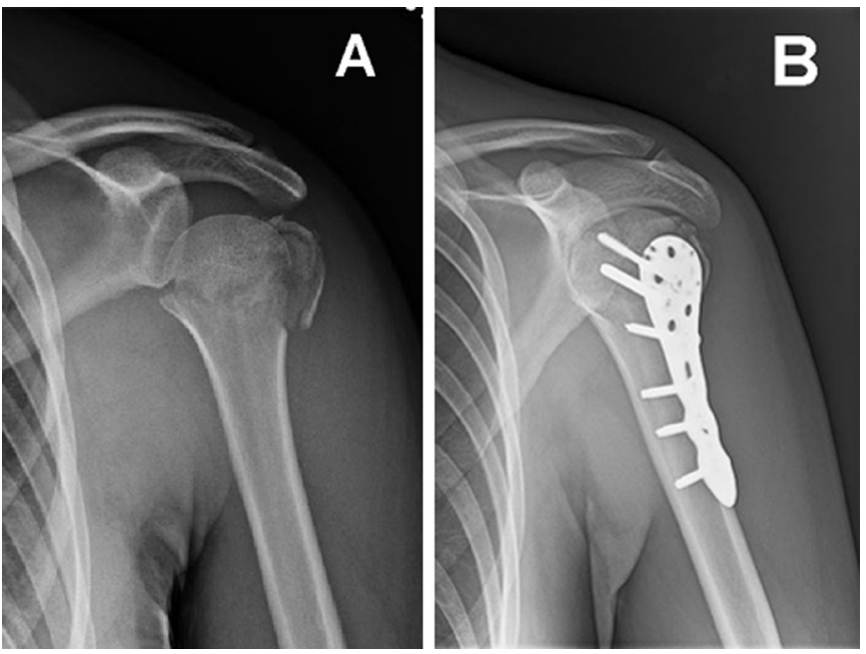

Figure 2 Radiographs showing (A) the patient's proximal humerus fracture, shown here 1 week after the closed reduction of the anterior glenohumeral dislocation and (B) treatment of the fracture with a metal plate and screws.
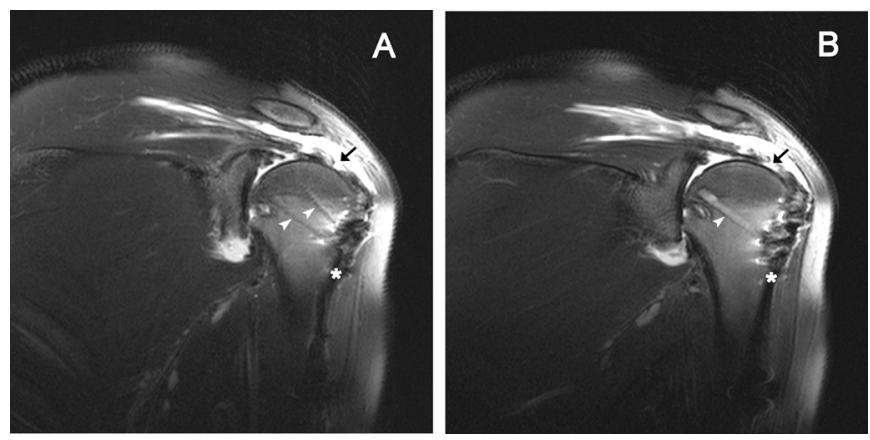

Figure 3 MR images of the patient's rotator cuff tear. The white arrow heads indicate metal screws that traverse from the plate $\left(^{*}\right)$ that is on the lateral surface of the upper humerus. The back arrows indicate the area of the supraspinatus tendon tear.

had essentially the same follow-up data at her 4-year and 5-year follow-ups; she had a lowered ability to perform in the 'sports/ performing arts module' of the Disabilities of the Arm, Shoulder and Hand (DASH). This was due to an inability to return to the same elite level of motocross performance as before. The limitation of motion was secondary to deltoid atrophy and was not attributable to fracture malunion (figure 5). However, she had made several adjustments to continue motocross racing including using a steering stabiliser on her motorcycle to reduce handlebar shaking and a foam-filled EVS (Walworth, Wisconsin, USA) brace to protect her left shoulder in case of falls during racing. She also regularly exercised with a BOSU ball (meaning BOth Sides Up; Hedstrom, Ashland, Ohio, USA) that she modified by

\begin{tabular}{|c|c|c|c|}
\hline & Before RCR* & $\begin{array}{l}3 \text { years after } \\
\text { RCR }^{*}\end{array}$ & \\
\hline $10 \mathrm{~cm}$ VAS score for pain & 0 & 2 & \\
\hline ASES score & 75 & 65 & (Best is 100) \\
\hline Simple shoulder test & nine out of 12 & 11 out of 12 & (12 is best) \\
\hline \multicolumn{4}{|l|}{ DASH score } \\
\hline Total & 23.3 & 16.7 & $\begin{array}{l}\text { (Best is } 0 \text {, worst is } \\
100 \text { ) }\end{array}$ \\
\hline Work & 0 & 0 & \\
\hline Sports/performing arts & 37.5 & 50 & \\
\hline \multicolumn{4}{|l|}{ Short-Form 36 (SF-36) } \\
\hline Physical functioning & 80 & 85 & (Best is 100 for all) \\
\hline Role physical & 25 & 100 & \\
\hline Bodily pain & 74 & 72 & \\
\hline General health & 80 & 100 & \\
\hline Vitality & 50 & 80 & \\
\hline Social functioning & 100 & 100 & \\
\hline Role emotional & 0 & 100 & \\
\hline Mental health & 76 & 88 & \\
\hline \multirow[t]{6}{*}{ Date } & Action & $\begin{array}{l}\text { Active range of } \\
\text { motion }\end{array}$ & \\
\hline & Forward flexion & 135 & \\
\hline & Abduction & 135 & \\
\hline & $\begin{array}{l}\text { External } \\
\text { rotation }\end{array}$ & 65 & \\
\hline & Internal rotation & 60 & \\
\hline & Extension & 45 & \\
\hline 4 years after injury & Adduction & 45 & \\
\hline
\end{tabular}

Skedros JG, et al. BMJ Case Rep 2018. doi:10.1136/bcr-2017-223692 


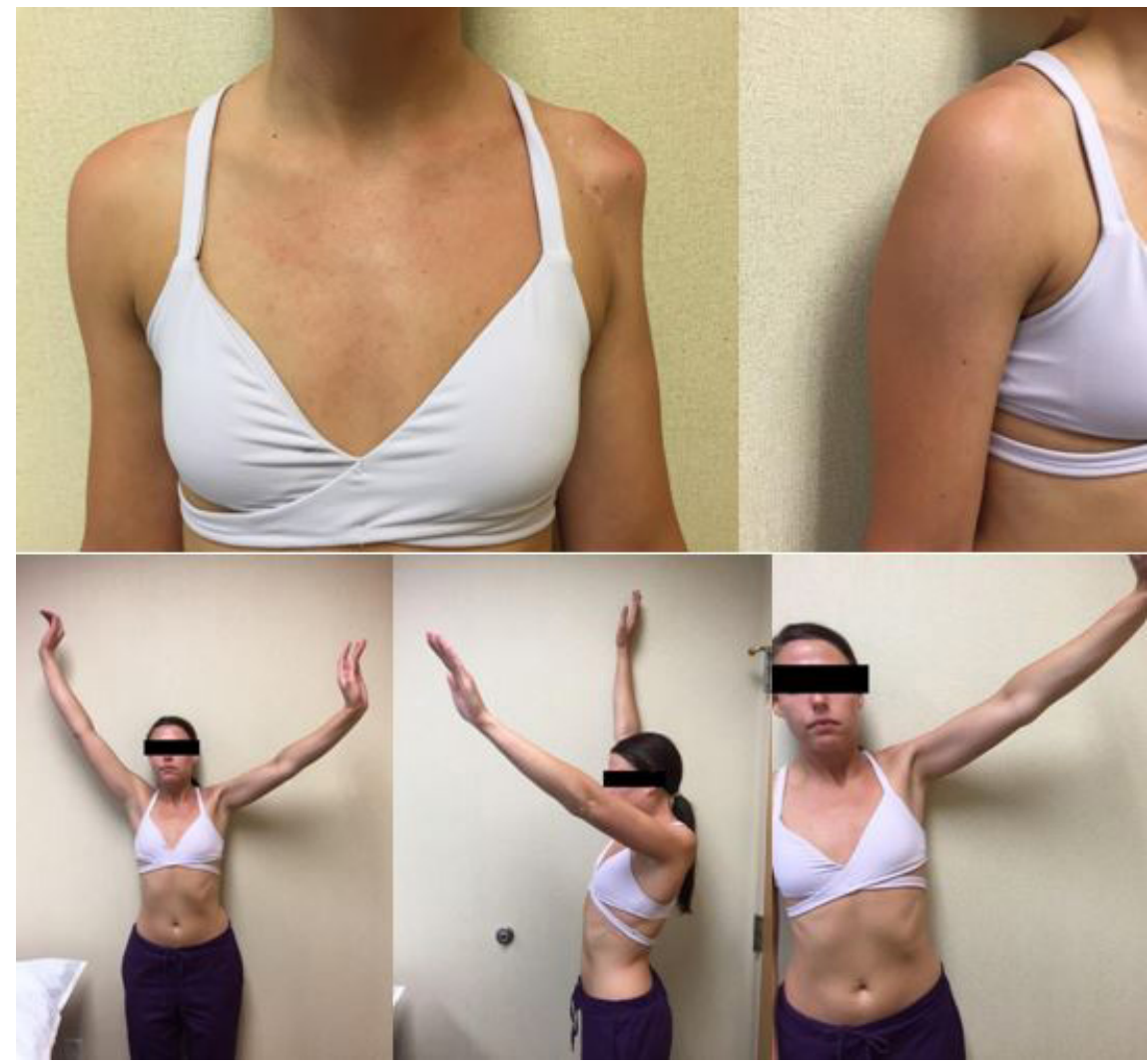

Figure 4 Photographs of our patient at the 4-year follow-up.

adding a motorcycle handlebar attachment. The BOSU ball is meant to create an unstable surface for resistance training. ${ }^{11}$

\section{DISCUSSION}

Although a triad of shoulder dislocation/fracture, axillary nerve injury and rotator cuff tear has been described as occurring during one traumatic event, our patient's rotator cuff tear occurred 13 months after her initial shoulder injury. The characteristics and timeframe of our patient's shoulder injuries and the long-term follow-up makes her case unique. There are studies that report long-term follow-up of patients with permanent complete or partial axillary neuropathy. One study showed that 11 out of 11 athletes with axillary nerve damage caused by tackling opposing players in football (9 out of 11) and hockey collisions ( 2 out of 11) never regained full nerve function (range of follow-up: 31-276 months). ${ }^{12}$ Although these patients never regained full nerve function, the majority ( 10 of 11 ) were able to return to their preinjury levels of activities, including professional athletics. Unlike our case, none of the 11 patients were reported to have
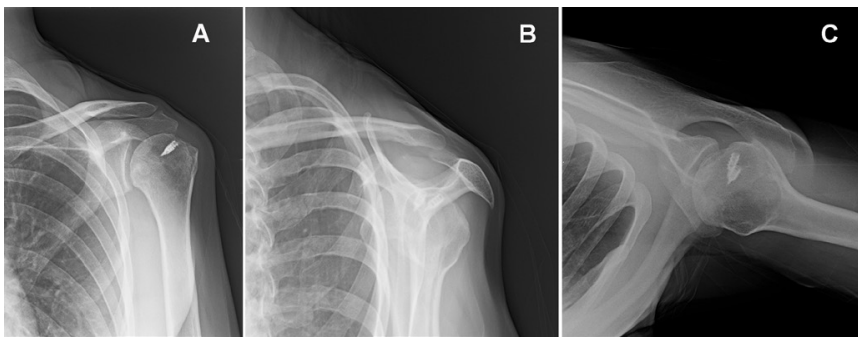

Figure 5 Radiographs obtained at 4-year follow-up. Metal suture anchors can be seen from the rotator cuff repair that was done 3 years prior. sustained a RCT during the time that their axillary neuropathy was deemed permanent. Another study described three cases of axillary nerve palsy (one of which occurred from a traumatic high speed motorcycle accident) in which all three patients eventually regained significant improvements in range of motion, even though there was complete denervation of the deltoid in all three cases. ${ }^{13}$ But unlike our patient, these three patients did not have a subsequent rotator cuff tear.

For patients with brachial plexus palsy and deltoid paralysis, trapezius transfer is a way to regain shoulder elevation. ${ }^{14}$ This procedure has been shown to increase range of motion and strengthen abduction and flexion. In addition, the trapezius transfer increases shoulder stability. Elhassan $e a l^{15}$ suggest that transfer of the lower trapezius is a potential solution for an irreparable posterosuperior rotator cuff tear. Although considered in our case, these types of procedures were not performed because our patient had already achieved superior ranges of flexion, abduction and external rotation compared with Elhassan and co-workers ${ }^{15}$ patients who underwent lower trapezius transfer. Furthermore, she did not have evidence of shoulder instability.

Our patient's better than expected range of active motion may be partially explained by her use of a modified BOSU ball. The literature on using unstable surfaces for resistance training and rehabilitation shows that while unstable surfaces may be the optimal exercise for athletes, they may be favourable for rehabilitation after shoulder injuries that result in significant weakness. ${ }^{11}$ Our patient created a BOSU ball with handlebar attachments to simulate motocross activity, and this may have enhanced her ability to fully return to motocross activities in addition to gaining shoulder motion and strength. This innovative approach to resistance training simulates the rough, uneven surfaces and the wobble or shimmy felt in the handlebars by an off-road motorcyclist. 
While our patient showed significant improvement in shoulder function, she still utilises several modifications that allow her to ride off-road motorcycles. These include a steering stabiliser that decreases the amount of wobble or shimmy felt by the rider and an EVS brand brace to protect her shoulder during motocross activity.

Our patient gained substantial improvement in shoulder function at 4-year and 5-year follow-ups despite having surgical repair of a subsequent full-thickness rotator cuff tear in the setting of permanent and complete axillary neuropathy. She has regained significant range of motion and was able to return to competing in motocross.

\section{Patient's perspective}

Although I have weakness raising my arm over my head, I have been able to work hard with my exercises and participate in motocross and other sports. I am also now a nurse, and I have no problem working in this capacity.

\section{Learning points}

- A full-thickness rotator cuff tear in the setting of permanent axillary nerve deficit can still be treated surgically with an acceptable outcome.

- Specialised exercises with the BOSU ball can help these patients achieve an acceptable result.

- A permanent axillary nerve deficit does not preclude participation in motocross racing.

Contributors All authors contributed to the drafting and critical revision of this manuscript, in addition to acquisition and interpretation of data. Each author has provided approval of the final version to be published.

Funding The authors have not declared a specific grant for this research from any funding agency in the public, commercial or not-for-profit sectors.

Competing interests None declared.

Patient consent Obtained.

Provenance and peer review Not commissioned; externally peer reviewed.
Open access This is an open access article distributed in accordance with the Creative Commons Attribution Non Commercial (CC BY-NC 4.0) license, which permits others to distribute, remix, adapt, build upon this work non-commercially, and license their derivative works on different terms, provided the original work is properly cited and the use is non-commercial. See: http://creativecommons.org/ licenses/by-nc/4.0/

(C) BMJ Publishing Group Ltd (unless otherwise stated in the text of the article) 2018. All rights reserved. No commercial use is permitted unless otherwise expressly granted.

\section{REFERENCES}

1 Malik S, Chiampas G, Leonard H. Emergent evaluation of injuries to the shoulder, clavicle, and humerus. Emerg Med Clin North Am 2010;28:739-63.

2 Visser CP, Coene LN, Brand R, et al. Nerve lesions in proximal humeral fractures. J Shoulder Elbow Surg 2001:10:421-7.

3 Coene LN. Mechanisms of brachial plexus lesions. Clin Neurol Neurosurg 1993;95 Suppl(Suppl):24-9.

4 Visser CP, Tavy DL, Coene LN, et al. Electromyographic findings in shoulder dislocations and fractures of the proximal humerus: comparison with clinical neurological examination. Clin Neurol Neurosurg 1999;101:86-91.

5 Güven O, Akbar Z, Yalçin S, et al. Concomitant rotator cuff tear and brachial plexus injury in association with anterior shoulder dislocation: unhappy triad of the shoulder. J Orthop Trauma 1994;8:429-30.

6 Groh Gl, Rockwood CA. The terrible triad: anterior dislocation of the shoulder associated with rupture of the rotator cuff and injury to the brachial plexus. J Shoulder Elbow Surg 1995;4:51-3.

7 Payne MW, Doherty TJ, Sequeira KA, et al. Peripheral nerve injury associated with shoulder trauma: a retrospective study and review of the literature. J Clin Neuromuscul Dis 2002;4:1-6.

8 Takase F, Inui A, Mifune Y, et al. Concurrent rotator cuff tear and axillary nerve palsy associated with anterior dislocation of the shoulder and large glenoid rim fracture: a "terrible tetrad". Case Rep Orthop 2014;2014:1-4.

9 Moser T, Lecours J, Michaud J, et al. The deltoid, a forgotten muscle of the shoulder. Skeletal Radiol 2013;42:1361-75.

10 Neer CS. Displaced proximal humeral fractures. I. Classification and evaluation. J Bone Joint Surg Am 1970;52:1077-89.

11 Behm D, Colado JC. The effectiveness of resistance training using unstable surfaces and devices for rehabilitation. Int I Sports Phys Ther 2012;7:226-41.

12 Perlmutter GS, Leffert RD, Zarins B. Direct injury to the axillary nerve in athletes playing contact sports. Am J Sports Med 1997;25:65-8.

13 Palmer SH, Ross AC. Case report. Recovery of shoulder movement in patients with complete axillary nerve palsy. Ann R Coll Surg Engl 1998;80:413-5.

14 Monreal R, Paredes L, Diaz H, et al. Trapezius transfer to treat flail shoulder after brachial plexus palsy. J Brachial Plex Peripher Nerve Inj 2007;2:2:2.

15 Elhassan BT, Wagner ER, Werthel JD. Outcome of lower trapezius transfer to reconstruct massive irreparable posterior-superior rotator cuff tear. I Shoulder Elbow Surg 2016;25:1346-53.

Copyright 2018 BMJ Publishing Group. All rights reserved. For permission to reuse any of this content visit

http://group.bmj.com/group/rights-licensing/permissions.

BMJ Case Report Fellows may re-use this article for personal use and teaching without any further permission.

Become a Fellow of BMJ Case Reports today and you can:

- Submit as many cases as you like

- Enjoy fast sympathetic peer review and rapid publication of accepted articles

- Access all the published articles

- Re-use any of the published material for personal use and teaching without further permission

For information on Institutional Fellowships contact consortiasales@bmjgroup.com

Visit casereports.bmj.com for more articles like this and to become a Fellow 